\title{
Colchicine for Recurrent Pericarditis (CORP)
}

\section{A Randomized Trial}

Massimo Imazio, MD; Antonio Brucato, MD; Roberto Cemin, MD; Stefania Ferrua, MD; Riccardo Belli, MD; Silvia Maestroni, MD; Rita Trinchero, MD; David H. Spodick, MD; and Yehuda Adler, MD, on behalf of the CORP (COlchicine for Recurrent Pericarditis) Investigators*

Background: Recurrence is the most common complication of pericarditis, affecting $10 \%$ to $50 \%$ of patients.

Objective: To evaluate the efficacy and safety of colchicine for the secondary prevention of recurrent pericarditis.

Design: Prospective, randomized, double-blind, placebocontrolled multicenter trial. (ClinicalTrials.gov registration number: NCT00128414)

Setting: 4 general hospitals in urban areas of Italy.

Patients: 120 patients with a first recurrence of pericarditis.

Intervention: In addition to conventional treatment, patients were randomly assigned to receive either placebo or colchicine, 1.0 to $2.0 \mathrm{mg}$ on the first day followed by a maintenance dose of 0.5 to $1.0 \mathrm{mg} / \mathrm{d}$, for 6 months.

Measurements: The primary study end point was the recurrence rate at 18 months. Secondary end points were symptom persistence at 72 hours, remission rate at 1 week, number of recurrences, time to first recurrence, disease-related hospitalization, cardiac tamponade, and rate of constrictive pericarditis.
Results: At 18 months, the recurrence rate was $24 \%$ in the colchicine group and $55 \%$ in the placebo group (absolute risk reduction, $0.31[95 \% \mathrm{Cl}, 0.13$ to 0.46$]$; relative risk reduction, $0.56[\mathrm{Cl}$, 0.27 to 0.73]; number needed to treat, $3[\mathrm{Cl}, 2$ to 7]). Colchicine reduced the persistence of symptoms at 72 hours (absolute risk reduction, $0.30[\mathrm{Cl}, 0.13$ to 0.45$]$; relative risk reduction, $0.56[\mathrm{Cl}$, 0.27 to 0.74$]$ ) and mean number of recurrences, increased the remission rate at 1 week, and prolonged the time to subsequent recurrence. The study groups had similar rates of side effects and drug withdrawal.

Limitation: Multiple recurrences and neoplastic or bacterial causes were excluded.

Conclusion: Colchicine is safe and effective for secondary prevention of recurrent pericarditis.

Primary Funding Source: Maria Vittoria Hospital, Torino, Italy.

Ann Intern Med. 2011;155:409-414.

www.annals.org

For author affiliations, see end of text.

* For a list of the CORP Investigators, see the Appendix (available at www .annals.org).

This article was published at www.annals.org on 28 August 2011
$\mathbf{R}$ ecurrent pericarditis is probably the most common and troublesome complication of acute pericarditis, occurring in $10 \%$ to $30 \%$ of patients with a first episode of acute pericarditis (1-3). The recurrence rate increases up to $50 \%$ after a first recurrence (4). Colchicine has shown promise for the secondary prevention of recurrent pericarditis in observational studies (5-7) and in the CORE (COlchicine for REcurrent pericarditis) trial (4), an open-label, singlecenter, randomized trial in which the drug halved the recurrence rate. Low dosages of colchicine $(0.5$ to $1.0 \mathrm{mg} / \mathrm{d})$ seem to be safe and effective for treating pericarditis $(1,4$, 8). However, no multicenter, double-blind, randomized trial has confirmed these favorable preliminary findings. The aim of the CORP (COlchicine for Recurrent Pericarditis) trial is to evaluate the efficacy and safety of colchicine as an adjunct to conventional therapy for the secondary prevention of recurrence in patients with a first recurrence of pericarditis (9).

\section{Methods}

The CORP trial is a prospective, randomized, doubleblind, placebo-controlled, multicenter trial to evaluate the efficacy and safety of colchicine for the treatment and prevention of recurrent pericarditis. Colchicine was considered as an adjunct to conventional therapy (9).

\section{Setting and Participants}

We enrolled 120 patients with a first recurrence of pericarditis from 4 general hospitals in Italy (Maria Vittoria Hospital, Torino; Ospedali Riuniti, Bergamo; San Maurizio Regional Hospital, Bolzano; and Ospedale SS Annunziata, Savigliano). All consecutive patients with a first recurrence of pericarditis were assessed for potential enrollment. Pericarditis was diagnosed by using available published criteria $(1,4,10,11)$, which include typical pericardial chest pain, pericardial friction rubs, widespread STsegment elevation or PR-segment depression that was not previously reported, and new or worsening pericardial effusion on echocardiography. A clinical diagnosis of acute pericarditis was made when at least 2 of these criteria were present (11). Recurrence was documented in patients who had recurrent chest pain and 1 or more of the following

See also:

Print

Editors' Notes . . . . . . . . . . . . . . . . . . . . . . . 410

Summary for Patients. . . . . . . . . . . . . . . . . . I-28

Web-Only

Appendix

Conversion of graphics into slides 


\section{Context}

Patients who have a recurrence of pericarditis are at high risk for subsequent episodes. Evidence regarding effective treatment and prevention are lacking.

\section{Contribution}

In this study, colchicine hastened the resolution of recurrent pericarditis and reduced the number of further recurrences.

\section{Caution}

Only patients with a first recurrence of pericarditis were studied.

\section{Implication}

Colchicine is useful for treatment and prevention after a first recurrence of pericarditis.

\section{-The Editors}

signs: fever; pericardial friction rubs; electrocardiographic changes; echocardiographic evidence of new or worsening pericardial effusion; or elevated leukocyte count, erythrocyte sedimentation rate, or C-reactive protein level (4). Patients were eligible if they had no contraindication to colchicine therapy, could provide informed consent, and had a favorable short-term prognosis. Inclusion criteria were a definite diagnosis of recurrent pericarditis (first recurrence), age 18 years or older, and provision of informed consent. The relevant institutional review boards and ethics committees approved our research protocol, and all participants gave written informed consent.

Patients were excluded if they were having their first episode of acute pericarditis or their second or subsequent recurrence or had pericarditis with tuberculous, purulent, or neoplastic causes; known severe liver disease; current aminotransferase levels greater than 1.5 times the upper limit of normal, current serum creatinine level greater than $221 \mu \mathrm{mol} / \mathrm{L}(2.5 \mathrm{mg} / \mathrm{dL})$; known myopathy; serum creatine kinase level above the upper limit of normal; known blood dyscrasias; gastrointestinal disease; or known hypersensitivity to colchicine. Also excluded were pregnant or lactating women (because of the contraindication to colchicine) and women in their childbearing years who were not using contraception. Finally, we excluded persons who were receiving or had previously received colchicine for any indication.

\section{Random Assignment and Interventions}

Participants were randomly assigned to treatment groups by a central computer-based automated sequence. Randomization was based on permuted blocks, with a block size of 4 . The random allocation sequence was implemented by using sequentially numbered containers. All participants and trial investigators were blinded to randomized treatment. Colchicine tablets contained $1 \mathrm{mg}$ of the active drug. All tablets were identical in color, shape, and taste; premarked to allow splitting into 2 equal parts; and provided in blister packs. Unblinded data were made available exclusively to an independent data and safety and monitoring board in the event of severe side effects. Data were collected by using case report and clinical events adjudication forms and were managed by investigators who were blinded to treatment assignments. A blinded clinical end point committee adjudicated all events.

Patients were randomly assigned to receive placebo or colchicine in addition to conventional treatment with aspirin, 800 to $1000 \mathrm{mg}$ (or ibuprofen, $600 \mathrm{mg}$ ) orally every 8 hours for 7 to 10 days, with gradual tapering over 3 to 4 weeks. Patients received colchicine, 1.0 to $2.0 \mathrm{mg}$, on the first day, followed by a maintenance dosage of 0.5 to 1.0 $\mathrm{mg} / \mathrm{d}$ for 6 months; all dosages were given as 2 doses 12 hours apart. Patients who weighed less than $70 \mathrm{~kg}$ or could not tolerate the highest dosage $(2.0 \mathrm{mg}$ followed by 1.0 $\mathrm{mg} / \mathrm{d})$ received a lower dosage $(0.5 \mathrm{mg}$ every 12 hours, followed by $0.5 \mathrm{mg}$ once daily). Gastrointestinal intolerance is a common cause of drug withdrawal. If symptoms of gastrointestinal intolerance (diarrhea, nausea, cramping, abdominal pain, or vomiting) persisted, the investigators could prescribe halving the dosage (by splitting the tablets)

Table 1. Baseline Participant Characteristics

\begin{tabular}{|c|c|c|}
\hline Characteristic & $\begin{array}{l}\text { Placebo Group } \\
(n=60)\end{array}$ & $\begin{array}{l}\text { Colchicine Group } \\
(n=60)\end{array}$ \\
\hline Mean age (SD), $y$ & $47.3(14.4)$ & $47.9(15.4)$ \\
\hline Men, $n(\%)$ & $29(48)$ & $34(43)$ \\
\hline Current smokers, $n(\%)$ & $25(42)$ & $26(56)$ \\
\hline Hypertension, $n(\%)$ & $15(25)$ & $12(20)$ \\
\hline Diabetes mellitus, $n(\%)$ & $1(2)$ & $2(3)$ \\
\hline $\begin{array}{l}\text { Chronic obstructive pulmonary } \\
\text { disease, } n(\%)\end{array}$ & $2(3)$ & $2(3)$ \\
\hline $\begin{array}{l}\text { Creatinine clearance }<60 \mathrm{~mL} / \mathrm{min} \\
\text { per } 1.73 \mathrm{~m}^{2}, n(\%)^{*}\end{array}$ & $2(3)$ & $4(7)$ \\
\hline Hypothyroidism, $n$ (\%) & $1(2)$ & $2(3)$ \\
\hline Previous idiopathic cause, $n(\%)$ & $48(80)$ & $50(83)$ \\
\hline $\begin{array}{l}\text { Previous autoimmune cause, } \\
\qquad n(\%) \dagger\end{array}$ & $12(20)$ & $10(17)$ \\
\hline $\begin{array}{l}\text { Previous use of corticosteroids, } \\
n(\%)\end{array}$ & $6(10)$ & $5(8)$ \\
\hline Previous cardiac surgery, $n(\%)$ & $4(7)$ & $3(5)$ \\
\hline $\begin{array}{l}\text { Previous myocardial infarction, } \\
\quad n(\%)\end{array}$ & $6(10)$ & $7(12)$ \\
\hline $\begin{array}{l}\text { Mean time from first episode } \\
\text { (SD), mo }\end{array}$ & $6.1(4.9)$ & $6.8(4.0)$ \\
\hline Fever, $n(\%)$ & $19(32)$ & $18(30)$ \\
\hline Pericarditic chest pain, $n(\%)$ & $60(100)$ & $60(100)$ \\
\hline Pericardial rub, $n(\%)$ & $13(22)$ & $12(20)$ \\
\hline Pericardial effusion, $n(\%)$ & $35(58)$ & $36(60)$ \\
\hline Mean ejection fraction (SD), \% & $58(4.2)$ & $58(6.2)$ \\
\hline $\begin{array}{l}\text { Elevated C-reactive protein level, } \\
n(\%) \neq \\
\text { Concomitant anti-inflammatory } \\
\text { therapy, } n(\%)\end{array}$ & $54(90)$ & $57(95)$ \\
\hline Aspirin or ibuprofen & $55(92)$ & $56(93)$ \\
\hline Prednisone & $5(8)$ & $4(7)$ \\
\hline
\end{tabular}

* Using the Cockroft-Gault equation; refers to the first episode of acute pericarditis.

† Includes inflammatory systemic diseases and postpericardiotomy syndromes. ‡ Defined as $>95.2 \mathrm{nmol} / \mathrm{L}$. 
without unmasking the randomization code. Therapy was discontinued if symptoms persisted at the lower dosage. The prescribed dosages of colchicine are based on previous studies $(1,4)$ that showed reduced side effects and improved drug tolerability compared with maintenance doses greater than $1.0 \mathrm{mg} / \mathrm{d}$.

Additional medical therapies were initiated on the basis of comorbid conditions (Table 1), existing practice guidelines, and local practice. Concomitant aspirin or ibuprofen was the first-choice anti-inflammatory medication. Patients with contraindications to aspirin (allergy, history of peptic ulcer or gastrointestinal bleeding, or a high or unacceptable risk for bleeding due to oral anticoagulant therapy) or who had aspirin intolerance received prednisone, 0.2 to $0.5 \mathrm{mg} / \mathrm{kg}$ of body weight per day for 4 weeks (12), and then the dosage was gradually tapered. When aspirin or another nonsteroidal anti-inflammatory drug was prescribed as combination therapy with placebo or colchicine, the patient also received a proton-pump inhibitor for gastroduodenal prophylaxis (9).

\section{Outcomes and Follow-up}

The primary study end point was the recurrence rate at 18 months. The secondary end points were symptom persistence at 72 hours, remission rate at 1 week, number of recurrences, time to first recurrence, disease-related hospitalization, cardiac tamponade, and rates of constrictive pericarditis. A blinded clinical end point committee adjudicated all end points.

Criteria for recurrence were the same as those for diagnosis of the first recurrence. Patients were considered to have remission when they were symptom-free and had no clinical, electrocardiographic, or echocardiographic signs of disease $(1,4)$. Treatment failure was considered if an unfavorable clinical reaction occurred, such as persistence of fever, appearance or worsening of pericardial effusion, or general illness lasting more than 7 days from the beginning of treatment $(1,4,9)$. Regularly scheduled study follow-up visits were performed at 1 week, 1 month, 3 months, 6 months, 12 months, and 18 months and included a medical visit; electrocardiography; echocardiography; blood chemistry with complete blood count; and assessment of C-reactive protein, creatinine, aminotransferase, and creatine levels.

\section{Safety}

During follow-up, all adverse events were monitored and recorded. An adverse event was considered severe if it was fatal or life-threatening, required hospitalization, or was significantly or permanently disabling or medically significant (that is, it could have jeopardized the patient or required medical or surgical intervention to prevent an adverse outcome). An adverse event was filed according to whether it was discovered by patient-reported symptoms or blood chemistry monitoring during follow-up visits. A safety monitoring committee whose members were masked to treatment assignment did an interim analysis after 60

www.annals.org
Figure 1. Study flow diagram.

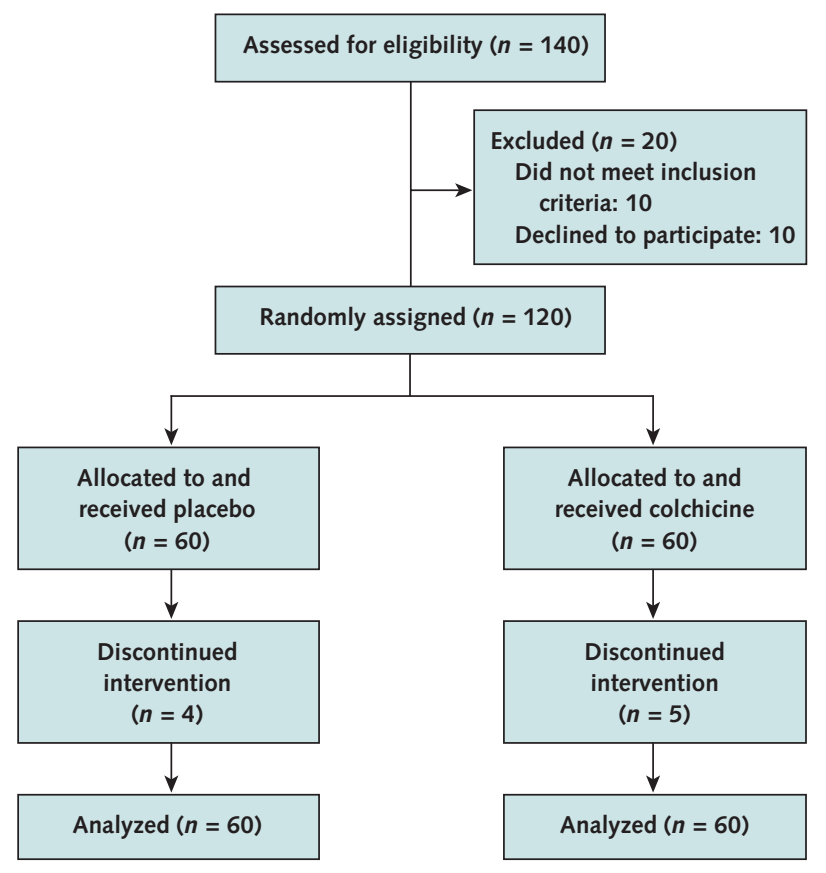

participants $(50 \%)$ were enrolled. Unmasking of the randomization code was allowed only when severe adverse events occurred.

\section{Statistical Analysis}

We needed 120 patients, 60 in each treatment group, to detect a $50 \%$ relative reduction in the risk for recurrence ( $50 \%$ in the placebo group vs. $25 \%$ in the colchicine group) with a power of $80 \%$, using a 2 -sided $\alpha$ value of 0.05 . The estimated $50.0 \%$ rate of recurrent pericarditis in the placebo group was based on the preliminary findings of the CORE trial (4). Analyses were performed by intention to treat.

Data were expressed as means (SDs). Patient groups were compared by using the Mann-Whitney test for continuous variables and a chi-square analysis for categorical variables. A $P$ value less than 0.05 indicated statistical significance. Time-to-event distributions were estimated by using the Kaplan-Meier method and compared by using the log-rank test. Analyses were performed with SPSS, version 13.0 (SPSS, Chicago, Illinois).

\section{Role of the Funding Source}

Our trial was an independent study founded and performed in the Italian National Healthcare System. The steering committee designed and oversaw the trial and had the final decision on the contents of the manuscript. All data were received, checked, and analyzed independently at the cardiology department of Maria Vittoria Hospital, Torino, Italy, after blinded adjudication of clinical events 


\begin{tabular}{|c|c|c|c|}
\hline End Point & $\begin{array}{l}\text { Placebo } \\
\text { Group } \\
(n=60)\end{array}$ & $\begin{array}{l}\text { Colchicine } \\
\text { Group } \\
(n=60)\end{array}$ & $P$ Value \\
\hline $\begin{array}{c}\text { Primary: recurrence rate } \\
\text { at } 18 \text { months, \% }\end{array}$ & 55 & 24 & $<0.001^{*}$ \\
\hline \multicolumn{4}{|l|}{ Secondary } \\
\hline $\begin{array}{l}\text { Symptom persistence at } \\
72 \mathrm{~h}, \%\end{array}$ & 53 & 23 & $0.001^{*}$ \\
\hline $\begin{array}{l}\text { Remission rate at } 1 \\
\text { week, \% }\end{array}$ & 48 & 82 & $<0.001^{*}$ \\
\hline $\begin{array}{l}\text { Median recurrences } \\
\quad(10 \text { th, 90th } \\
\text { percentile), } n\end{array}$ & $1.0(0.0,3.0)$ & $0.1(0.0,1.0)$ & $<0.001$ \\
\hline $\begin{array}{l}\text { Median time to first } \\
\text { recurrence (10th, } \\
\text { 90th percentile), mo }\end{array}$ & $1.0(0.0,5.5)$ & $2.5(0.0,19.1)$ & $<0.001$ \\
\hline $\begin{array}{l}\text { Disease-related } \\
\quad \text { hospitalization, } n(\%)\end{array}$ & $8(13)$ & $3(5)$ & 0.20 \\
\hline $\begin{array}{l}\text { Cardiac tamponade, } \\
n(\%)\end{array}$ & $1(2)$ & $0(0)$ & $>0.99$ \\
\hline $\begin{array}{l}\text { Constrictive pericarditis, } \\
n(\%)\end{array}$ & $0(0)$ & $0(0)$ & $>0.99$ \\
\hline $\begin{array}{l}\text { Mean follow-up (SD), } \\
\text { mo }\end{array}$ & $23.7(12.6)$ & $21.9(9.4)$ & 0.38 \\
\hline
\end{tabular}

* Calculated by using Cox regression analysis.

and side effects. Acarpia (Madeira, Portugal) provided the drug and placebo as an unrestricted grant.

\section{RESULTS}

Patients were recruited between August 2005 and April 2009, and the trial was completed in October 2010 after the last planned follow-up (18 months after random assignment of the last enrolled patient). Baseline patient characteristics were similar between the 2 study groups (Table 1). Figure 1 shows a detailed flow diagram of the study.

All patients who tolerated treatment with colchicine or placebo discontinued therapy at 6 months, as planned. No open-label colchicine was administered after the end of the experimental treatment. No patient was lost to follow-up, and all participants were analyzed for outcomes according to their original assigned groups.

At 18 months, the recurrence rate was $24 \%$ in the colchicine group and $55 \%$ in the placebo group (absolute risk reduction, 0.31 [ $95 \% \mathrm{CI}, 0.13$ to 0.46 ]; relative risk reduction, 0.56 [CI, 0.27 to 0.73$]$; number needed to treat, 3 [CI, 2 to 7$]$ ). Colchicine also significantly reduced the persistence of symptoms at 72 hours (absolute risk reduction, 0.30 [CI, 0.13 to 0.45 ]; relative risk reduction, 0.56 [CI, 0.27 to 0.74$]$ ) and the mean number of recurrences, increased the remission rate at 1 week, and prolonged the time to recurrence (Table 2). During a mean follow-up of more than 20 months, no cases of constrictive pericarditis occurred in the study groups. Figure 2 shows the recurrence-free survival rate by treatment group.

The colchicine and placebo groups had similar rates of side effects $(7 \%$ vs. $7 \% ; P>0.99)$ and drug withdrawal $412 \mid 4$ October 2011 Annals of Internal Medicine $\mid$ Volume 155 • Number 7
( $8 \%$ vs. $5 \% ; P=0.89)$. No severe side effects occurred. All side effects were recorded in the first week of treatment. Gastrointestinal intolerance was the main side effect during the study $(7 \%$ in the colchicine group and $5 \%$ in the placebo group), although 1 case of hepatotoxicity (2\%) related to concomitant hepatobiliary tract disease was observed in the placebo group.

Colchicine therapy was discontinued in 5 patients $(8 \%)$. A medical decision was the main cause of drug withdrawal in 4 of these cases (80\%), as well as for all cases in the placebo group. Table 3 lists side effects and drug withdrawal data.

\section{DISCUSSION}

In the CORP trial, colchicine as an adjunct to conventional anti-inflammatory therapy halved the recurrence rate of pericarditis at 18 months after a first episode reduced the number of recurrences, and prolonged the time to subsequent recurrence, with no significant or severe side effects. The placebo and treatment groups had similar rates of side effects, with gastrointestinal intolerance (the main side effect) occurring in up to $7 \%$ of cases. To our knowledge, this is the first multicenter, double-blind, randomized trial to show such efficacy and safety for colchicine.

The exact mechanism of the therapeutic and preventive effects on pericarditis is not fully understood. Most of the pharmacologic effects on cells involved in inflammation seem to be related to its ability to disrupt microtubules and to concentrate in leukocytes, especially granulocytes, where its peak concentration may be more than 16 times

Figure 2. Kaplan-Meier recurrence-free survival rates, by study group.

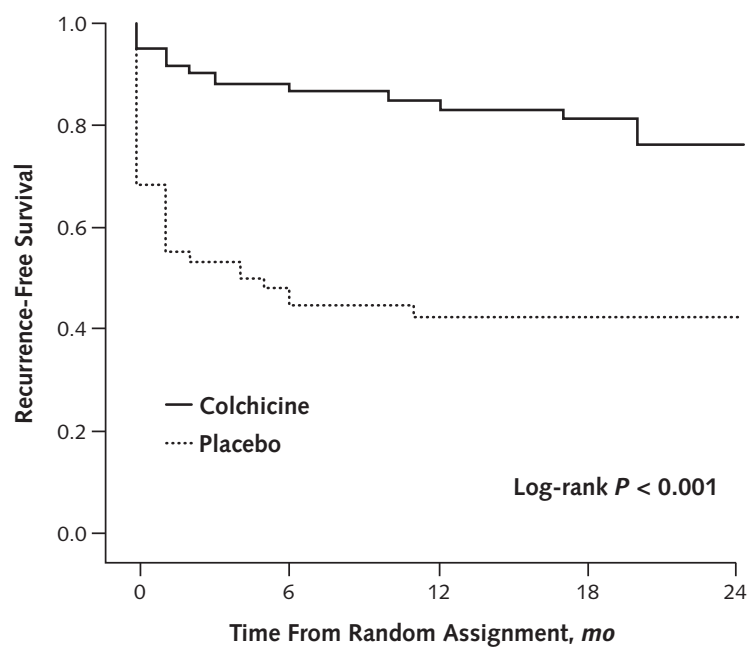

Patients at risk, $n$

$\begin{array}{llllll}\text { Colchicine } & 60 & 53 & 47 & 43 & 10 \\ \text { Placebo } & 60 & 28 & 22 & 19 & 10\end{array}$


Colchicine for Recurrent Pericarditis (CORP) $\mid$ ORIGINAL RESEARCH

the peak concentration in plasma- even at low oral doses $(2,8)$. Colchicine inhibits the process of microtubule selfassembly by binding $\beta$-tubulin into tubulin-colchicine complexes. By inhibiting the movement of intracellular granules and the secretion of various substances, colchicine inhibits various leukocyte functions and exhibits an antiinflammatory action that overcomes possible toxic effects at low oral doses $(2,8,13)$.

On the basis of limited evidence, experts have recommended the use of colchicine for the treatment and prevention of pericarditis $(3,8,10,11)$. Colchicine has been proposed as a first-line treatment for recurrent pericarditis (class I indication) and an optional treatment for acute pericarditis (class IIa indication) in the 2004 European guidelines on the management of pericardial diseases (14). However, these recommendations are based on nonrandomized studies that lacked control groups (Table 4). Two studies published since these recommendations were made, the COlchicine for PEricarditis (COPE) and CORE trials $(1,4)$, were open-label, single-center trials. The COPE trial (1) evaluated 120 patients and found that colchicine, 0.5 to $1 \mathrm{mg} / \mathrm{d}$ for 3 months, was an effective adjunct to conventional therapy for the primary prevention of recurrent pericarditis (rates at 18 months, $11 \%$ in the colchicine group vs. $32 \%$ in the group that did not receive colchicine; $P=0.004$; number needed to treat, 5.0) and persistence of symptoms at 72 hours ( $12 \%$ vs. $37 \% ; P=0.003)$. Similar to our findings, gastrointestinal side effects were most common, and colchicine therapy was discontinued in $8 \%$ of patients because of diarrhea. In the CORE trial (4), 84 patients who received colchicine, 0.5 to $1 \mathrm{mg} / \mathrm{d}$ for 6 months as an adjunct to conventional treatment, also had reduced rates of recurrent pericarditis at 18 months $(24 \%$ in the colchicine group vs. $51 \%$ in the group that did not receive colchicine; $P=0.022$; number needed to treat, 4.0 [CI, 2.5 to 7.1$]$ ) and persistence of symptoms at 72 hours (10\% vs. $31 \% ; P=0.029)$.

Current guidelines recommend colchicine dosages of 2 $\mathrm{mg} / \mathrm{d}$ for 1 to 2 days, followed by a maintenance dose of 1 $\mathrm{mg} / \mathrm{d}$. The CORE and COPE trials used a maintenance dose of $0.5 \mathrm{mg}$ twice daily, which was reduced to $0.5 \mathrm{mg} / \mathrm{d}$ in patients weighing less than $70 \mathrm{~kg}$; thus, lower doses may
Table 3. Overall Incidence and Types of Adverse Effects

\begin{tabular}{lll}
\hline Adverse Effect & $\begin{array}{l}\text { Placebo Group } \\
(\boldsymbol{n}=60), \boldsymbol{n}(\%)\end{array}$ & $\begin{array}{l}\text { Colchicine Group } \\
(\boldsymbol{n}=60), \boldsymbol{n}(\%)\end{array}$ \\
\hline Overall & $4(7)$ & $4(7)$ \\
\hline Gastrointestinal intolerance & $3(5)$ & $4(7)$ \\
\hline Hepatoxicity & $1(2)$ & $0(0)$ \\
\hline Myotoxicity & $0(0)$ & $0(0)$ \\
Alopecia & $0(0)$ & $0(0)$ \\
\hline Other & $0(0)$ & $0(0)$ \\
Severe side effects & $0(0)$ & $0(0)$ \\
Drug withdrawal & $4(7)$ & $5(8)$ \\
\hline Physician decision & $4(7)$ & $4(7)$ \\
\hline Patient decision & $0(0)$ & $1(2)$ \\
\hline
\end{tabular}

* Diarrhea, nausea, cramping, abdominal pain, or vomiting.

† Any elevation of aminotransferase levels above the normal reference range.

be equally effective and have a lower rate of side effects. The CORP trial confirms the previously shown benefits of colchicine for preventing recurrent pericarditis when used at lower doses by demonstrating similar efficacy and tolerability.

Our study has limitations. Our findings might not be generalizable to other settings or other patient populations. The CORP trial addressed the use of colchicine only after the first recurrence of pericarditis and not in patients who had already had multiple recurrences. We also excluded patients with elevated aminotransferase or creatinine levels, severe liver disease, myopathy, blood dyscrasias, or gastrointestinal disease. Our results should not be applied to women who are pregnant or lactating or those in their childbearing years and who are not using sufficient contraception. Because we recruited only adults, our results do not apply to children. We also excluded patients with bacterial or neoplastic pericarditis; thus, the efficacy and safety of colchicine has been shown only in a well-defined group of patients with recurrent pericarditis. Of note, colchicine is not approved for the prevention of pericarditis in North America or Europe, and its use as such is off-label. Finally, although we found a significant reduction in our primary and secondary outcomes, our limited sample size might have precluded the identification of certain adverse effects.

\section{Table 4. Main Published Studies on the Use of Colchicine to Treat Recurrent Pericarditis}

\begin{tabular}{|c|c|c|c|c|c|c|}
\hline $\begin{array}{l}\text { Study, Year } \\
\text { (Reference) }\end{array}$ & Study Design & $\begin{array}{l}\text { Patients, } \\
n^{*}\end{array}$ & $\begin{array}{l}\text { Maintenance } \\
\text { Dosage, } m g / d\end{array}$ & $\begin{array}{l}\text { Adjunct to } \\
\text { Standard Therapy }\end{array}$ & $\begin{array}{l}\text { Follow-up, } \\
\text { mo }\end{array}$ & $\begin{array}{l}\text { Recurrence Rate, } \\
n / N(\%)\end{array}$ \\
\hline Guindo et al, 1990 (5) & Nonrandomized, case series & 9 & 1.0 & Yes & $10-54$ & $0 / 9(0)$ \\
\hline Adler et al, 1994 (6) & Nonrandomized, case series & 8 & 1.0 & Yes & $18-34$ & $0 / 8(0)$ \\
\hline Millaire et al, 1994 (7) & Nonrandomized, case series & 19 & 1.0 & No & $32-44$ & $4 / 19(21)$ \\
\hline Adler et al, 1998 (2) & Nonrandomized, case series & 51 & 1.0 & Yes & $6-128$ & $7 / 51(14)$ \\
\hline Imazio et al, 2005 (13) & Nonrandomized, case series & 35 & 1.0 & Yes & $48-108$ & $3 / 35(9)$ \\
\hline Imazio et al, 2005 (4) & Randomized, open-label, single-center & $84+$ & $0.5-1.0$ & Yes & $8-44$ & $9 / 42(21)$ vs. $19 / 42(45) \neq$ \\
\hline
\end{tabular}

* All patients had recurrent pericarditis.

† Only patients having a first recurrence of pericarditis were recruited.

\# Recurrence rate at $18 \mathrm{mo:} 24 \%$ vs. $51 \%(P=0.02)$. 
Several items require further investigation. First, the specific mechanism by which colchicine prevents pericarditis requires further clarification in both basic and clinical research. Second, although colchicine therapy seems promising for recurrent pericarditis, additional research is needed to clarify its possible use for an initial acute episode of pericarditis. The ICAP (Investigation on Colchicine for Acute Pericarditis) trial, a multicenter, double-blind, randomized trial, should provide further evidence for or against this indication (15). Third, a sustained antiinflammatory effect of colchicine may be beneficial in forms of pericarditis that are related to autoimmune pathogeneses, but it remains unclear whether interference of colchicine with leukocyte function may delay the clearance of causative pathogens in infectious causes of pericarditis, such as a virus. Finally, further research is needed to identify the best duration of colchicine treatment. Because recurrences have been described after discontinuation of colchicine therapy, some investigators (16-20) advocate longer use: up to 12 to 24 months after the last recurrence, tailored to each patient, with gradual tapering in more severe cases of recurrent pericarditis.

In summary, adding colchicine to empirical antiinflammatory therapy seems to be an inexpensive and safe means to hasten symptom resolution, improve remission rates by 1 week, and reduce recurrence after an initial recurrence of pericarditis.

From Maria Vittoria Hospital and Ospedale degli Infermi, Torino, Ospedali Riuniti, Bergamo, San Maurizio Regional Hospital, Bolzano, and SS Annunziata Hospital, Savigliano, Italy; St. Vincent Hospital, University of Massachusetts, Worcester, Massachusetts; and Tel Aviv University, Tel Aviv, and Misgav Ladach Hospital, Jerusalem, Israel.

Acknowledgment: The authors thank the study participants, as well as the physicians, nurses, ethical committees, and administrative staff in the hospitals who assisted in conducting the study.

Potential Conflicts of Interest: Disclosures can be viewed at www.acponline .org/authors/icmje/ConflictOflnterestForms.do?msNum=M11-0907.

Reproducible Research Statement: Study protocol: Available from Dr. Imazio (e-mail, massimo_imazio@yahoo.it). Statistical code and data set: Available from Dr. Imazio (e-mail, massimo_imazio@yahoo.it) for personal use, with approval from the Steering Committee.

Requests for Single Reprints: Massimo Imazio, MD, Cardiology Department, Maria Vittoria Hospital, Via Cibrario 72, 10141 Torino, Italy; e-mail, massimo_imazio@yahoo.it.

Current author addresses and author contributions are available at www .annals.org.

\section{References}

1. Imazio M, Bobbio M, Cecchi E, Demarie D, Demichelis B, Pomari F, et al. Colchicine in addition to conventional therapy for acute pericarditis: results of the
COlchicine for acute PEricarditis (COPE) trial. Circulation. 2005;112:2012-6. [PMID: 16186437]

2. Adler Y, Finkelstein Y, Guindo J, Rodriguez de la Serna A, Shoenfeld Y, Bayes-Genis A, et al. Colchicine treatment for recurrent pericarditis. A decade of experience. Circulation. 1998;97:2183-5. [PMID: 9626180]

3. Adler Y, Imazio M. Recurrent Pericarditis. Waltham, MA: UpToDate; 2010. Accessed at www.uptodate.com/contents/recurrent-pericarditis on 2 August 2011.

4. Imazio M, Bobbio M, Cecchi E, Demarie D, Pomari F, Moratti M, et al. Colchicine as first-choice therapy for recurrent pericarditis: results of the CORE (COlchicine for REcurrent pericarditis) trial. Arch Intern Med. 2005;165:198791. [PMID: 16186468]

5. Guindo J, Rodriguez de la Serna A, Ramió J, de Miguel Diaz MA, Subirana MT, Perez Ayuso MJ, et al. Recurrent pericarditis. Relief with colchicine. Circulation. 1990;82:1117-20. [PMID: 2205414]

6. Adler Y, Zandman-Goddard G, Ravid M, Avidan B, Zemer D, Ehrenfeld M, et al. Usefulness of colchicine in preventing recurrences of pericarditis. Am J Cardiol. 1994;73:916-7. [PMID: 8184826]

7. Millaire A, de Groote P, Decoulx E, Goullard L, Ducloux G. Treatment of recurrent pericarditis with colchicine. Eur Heart J. 1994;15:120-4. [PMID: 8174571]

8. Imazio M, Brucato A, Trinchero R, Spodick D, Adler Y. Colchicine for pericarditis: hype or hope? Eur Heart J. 2009;30:532-9. [PMID: 19190012] 9. Imazio M, Cecchi E, Ierna S, Trinchero R; CORP Investigators. CORP (COlchicine for Recurrent Pericarditis) and CORP-2 trials-two randomized placebo-controlled trials evaluating the clinical benefits of colchicine as adjunct to conventional therapy in the treatment and prevention of recurrent pericarditis: study design and rationale. J Cardiovasc Med (Hagerstown). 2007;8:830-4. [PMID: 17885522]

10. Imazio M, Brucato A, Trinchero R, Adler Y. Diagnosis and management of pericardial diseases. Nat Rev Cardiol. 2009;6:743-51. [PMID: 19859068]

11. Imazio M, Spodick DH, Brucato A, Trinchero R, Adler Y. Controversial issues in the management of pericardial diseases. Circulation. 2010;121:916-28. [PMID: 20177006]

12. Imazio M, Brucato A, Cumetti D, Brambilla G, Demichelis B, Ferro S, et al. Corticosteroids for recurrent pericarditis: high versus low doses: a nonrandomized observation. Circulation. 2008;118:667-71. [PMID: 18645054]

13. Imazio M, Demichelis B, Parrini I, Cecchi E, Demarie D, Ghisio A, et al. Management, risk factors, and outcomes in recurrent pericarditis. Am J Cardiol. 2005;96:736-9. [PMID: 16125506]

14. Maisch B, Seferović PM, Ristić AD, Erbel R, Rienmüller R, Adler Y, et al; Task Force on the Diagnosis and Management of Pricardial Diseases of the European Society of Cardiology. Guidelines on the diagnosis and management of pericardial diseases executive summary; The Task Force on the Diagnosis and Management of Pericardial Diseases of the European Society of Cardiology. Eur Heart J. 2004;25:587-610. [PMID: 15120056]

15. Imazio M, Cecchi E, Ierna S, Trinchero R; ICAP Investigators. Investigation on Colchicine for Acute Pericarditis: a multicenter randomized placebocontrolled trial evaluating the clinical benefits of colchicine as adjunct to conventional therapy in the treatment and prevention of pericarditis; study design and rationale. J Cardiovasc Med (Hagerstown). 2007;8:613-7. [PMID: 17667033] 16. Brucato A, Brambilla G, Moreo A, Alberti A, Munforti C, Ghirardello A, et al. Long-term outcomes in difficult-to-treat patients with recurrent pericarditis. Am J Cardiol. 2006;98:267-71. [PMID: 16828606]

17. Brucato A, Brambilla G, Adler Y, Spodick DH, Canesi B. Therapy for recurrent acute pericarditis: a rheumatological solution? Clin Exp Rheumatol. 2006;24:45-50. [PMID: 16539818]

18. Brucato A, Brambilla G, Adler Y, Spodick DH. Colchicine for recurrent acute pericarditis [Letter]. Arch Intern Med. 2006;166:696. [PMID: 16567611] 19. Imazio M, Brucato A, Trinchero R, Spodick D, Adler Y. Individualized therapy for pericarditis. Expert Rev Cardiovasc Ther. 2009;7:965-75. [PMID: 19673674]

20. Imazio M, Brucato A, Mayosi BM, Derosa FG, Lestuzzi C, Macor A, et al. Medical therapy of pericardial diseases: part I: idiopathic and infectious pericarditis. J Cardiovasc Med (Hagerstown). 2010;11:712-22. [PMID: 20736783] 


\section{Annals of Internal Medicine}

Current Author Addresses: Drs. Imazio, Belli, and Trinchero: Cardiology Department, Maria Vittoria Hospital, Via Cibrario 72, 10141 Torino, Italy.

Drs. Brucato and Maestroni: Ospedali Riuniti, Largo Barozzi 1, 24128 Bergamo, Italy.

Dr. Cemin: Cardiology Department, Regional General Hospital, San Maurizio, Via Lorenz Böhler 5, 39100 Bolzano, Italy.

Dr. Ferrua: Cardiology Department, Ospedale degli Infermi, Via Rivalta 29, 10098 Rivoli (Torino), Italy.

Dr. Spodick: St. Vincent Hospital, 123 Summer Street, Worcester, MA 01608.

Dr. Adler: Misgav Ladach Hospital, 27 King Hiskiyahu Street, Jerusalem, Israel.

Author Contributions: Conception and design: M. Imazio, S. Maestroni, R. Trincherio.

Analysis and interpretation of the data: M. Imazio, A. Brucato, S. Maestroni, R. Trinchero, D.H. Spodick, Y. Adler.

Drafting of the article: M. Imazio, A. Brucato, R. Cemin, D.H. Spodick. Critical revision of the article for important intellectual content: $\mathrm{M}$. Imazio, A. Brucato, R. Cemin, R. Belli, R. Trinchero, Y. Adler.

Final approval of the article: M. Imazio, A. Brucato, R. Cemin, S. Ferrua, R. Belli, R. Trinchero, Y. Adler.

Provision of study materials or patients: M. Imazio, A. Brucato, R. Cemin, S. Ferrua, R. Belli, R. Trinchero.

Statistical expertise: M. Imazio, R. Cemin.

Obtaining of funding: M. Imazio, R. Belli, R. Trinchero.

Administrative, technical, or logistic support: M. Imazio, R. Belli, S. Maestroni, R. Trinchero.

Collection and assembly of data: M. Imazio, A. Brucato, R. Cemin, S. Ferrua, S. Maestroni.

\section{APPENDIX}

\section{Committees}

Steering Committee: Rita Trinchero, MD, Torino, Italy (Chair); Massimo Imazio, MD, Torino, Italy (Co-Chair and Principal Investigator); and the nucleus members of the Study Group on Heart and Infectious Diseases of the Associazione Nazionale Medici Cardiologi Ospedalieri (ANMCO).

Safety and Clinical Events Committee: Yehuda Adler, MD, Tel Hashomer, Israel (Coordinator); Ralph Shabetai, MD, San Diego, California; and David H. Spodick, MD, Worcester, Massachusetts.

\section{Recruiting Centers and Investigators}

Cardiology Department, Maria Vittoria Hospital, Torino, Italy (coordinating center): M. Imazio, D. Forno, S. Ferro, and R. Belli.

Ospedali Riuniti, Bergamo, Italy: A. Brucato, S. Maestroni, and D. Cumetti.

Department of Cardiology, San Maurizio Regional Hospital, Bolzano, Italy: R. Cemin.

Ospedale SS Annunziata, Savigliano, Italy: S. Ferrua, A. Bassignana, and B. Doronzo. 